\title{
Physicians must be brought up to speed on concussion risks
}

$\mathrm{C}$ anadian physicians have often been uninformed about the long-term consequences of concussions suffered in sport, a specialist in athletic injuries argues.

There's a desperate need to educate physicians about the consequences of concussions, Dr. Jaime Kissick, former head physician for the Ottawa Senators hockey club and a specialist in athlete concussions at the Ottawa Sport Medicine Centre in Ontario told a special seminar on concussions in hockey held at Scotiabank Place in December 2011.

Physicians are in the dark about concussions as much as everyone else, he said. "One of the very real challenges we have is educating the medical profession. We are working hard at trying to educate them about the importance of concussion diagnosis, management, and return-to-play plans."

With the evidence continuing to mount on the negative long-term consequences of head injuries, panelists at the session said that doctors and sports organizations across the globe are scrambling to raise awareness and funds needed to establish policies and procedures required to address the problem.

As a result of the publicity accorded to hockey superstar Sidney Crosby's prolonged absence from the game as a result of concussion, and growing indications that there are severe, long-term effects from head injuries, the sport has had little option but to take the injury more seriously, added Dr. Mark Aubry, chief medical officer for Hockey Canada. "We're getting more severe in our return-to-play guidelines because we're learning more about the injury. We're realizing it doesn't heal that fast, and what may appear mild, may be more severe and prolonged than you think."

The severity of those consequences is becoming ever more apparent, said Dr. Kristian Goulet, medical director at the Eastern Ontario Concussion Clinic and the Pediatric Sports Medicine Clinic of Ottawa. Every year in the

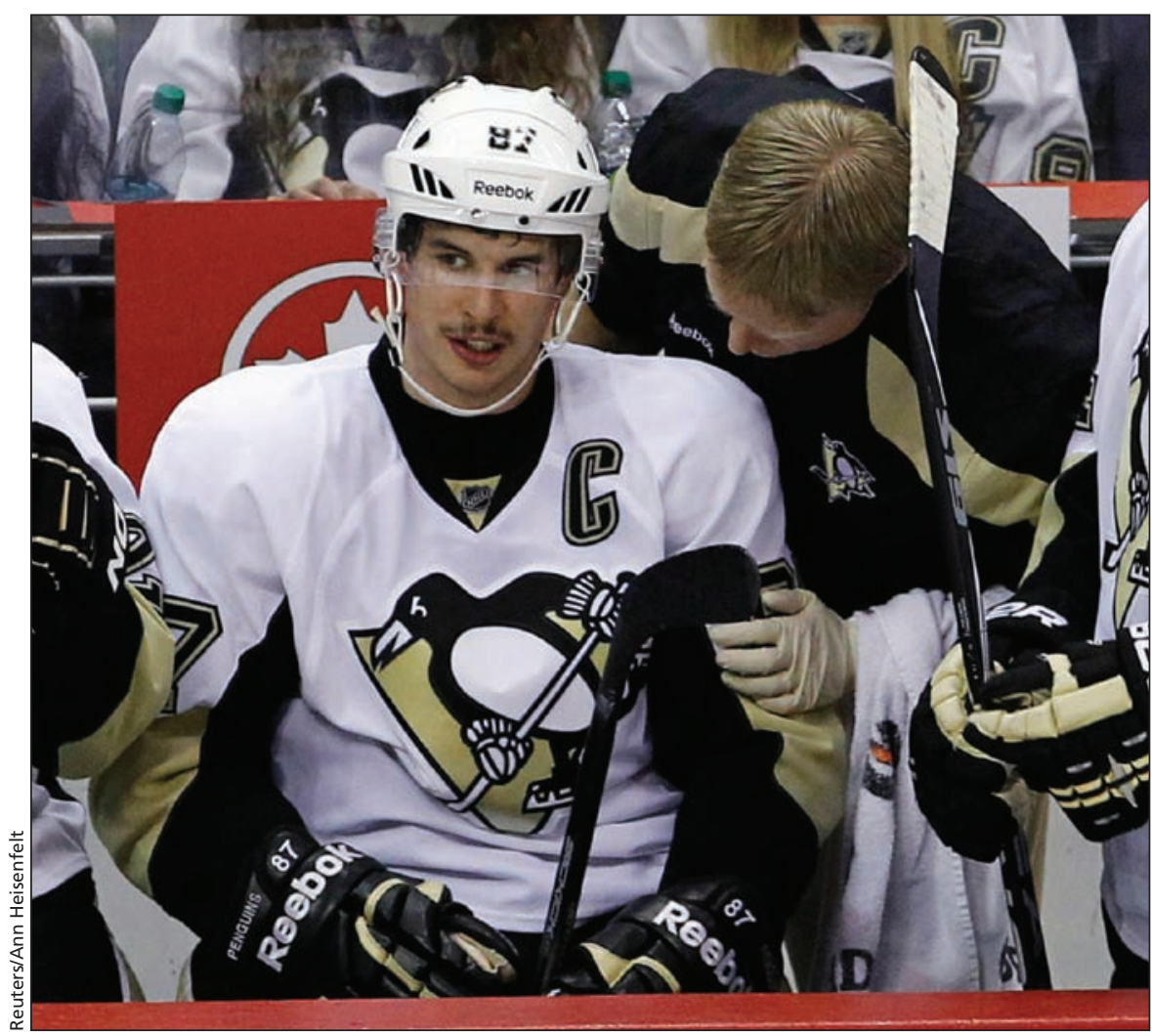

As a result of the publicity accorded to hockey superstar Sidney Crosby's prolonged absence from the game, the sport may have little option but to take the injury more seriously.

United States, "225000 new patients are showing effects of long-term head injury. This isn't necessarily just mild headaches, but chronic depression, substance abuse, and dementia as well."

Changes to hockey rules haven't been rapidly implemented as evidence of such consequences has emerged. But the panelists argued that part of the reason for the delay is that people were unaware of the long-term consequences of head injuries.

"It's an invisible injury," Kissick noted, adding that "the way we treat concussions today is certainly a lot different than how we treated them years ago. It was a problem that existed before, but people didn't understand because we didn't have the education."

Part of that problem has been that players' symptoms recede and they are often eager to get back out on to the ice,
Aubry said. But $30 \%$ of those players score abnormally on neuropsychological tests, he added. "This means cognitive recovery may follow the resolution of symptoms. And we should probably be keeping our athletes out that much longer."

Despite the evidence of high risk involved in returning to play too early, National Hockey League (NHL) physicians are still in disagreement about when players should be allowed to suit up, Aubry added.

There's a desperate need to educate players, physicians, parents and others in the hockey community about the consequences of concussions, the panelists said.

To that end, the Canadian Medical Association and the Canadian Academy of Sport and Exercise Medicine cohosted a workshop for physicians 
in December 2011 which brought together representatives from major national physician groups as a part of bid to collaboratively develop guidelines to optimize the care of concussed patients, Kissick said.'It's a way to put everybody's resources together. The plan is to come up with some very good learning modules for Canadian physicians." The groups are seeking funding from the NHL Players' Association to help develop the treatment guidelines.

While critics charge that hockey officials and aficionados have been slow to embrace such changes as bans on fighting and intentional head hits, or to impose new equipment requirements such as extra padding for helmets or softer body padding, Aubry argued at the Scotiabank Place session that Hockey
Canada has been one of the agents of change.

Association rules adopted this season have "zero tolerance" for hits above the shoulder, he said. "Every head hit has a consequence and should be punished, regardless of whether it's accidental or not. There's no grey area, we need to respect players' heads." Hockey Canada also recommended that teams organize preseason seminars on concussions to better inform players, parents, trainers and coaches about concussion risks.

While the association also recommends that concussed players get a "return-to-play note" from their doctor before getting back on the ice, Canadian oversight of the game appears to be lagging behind the US. Some 17 states have passed laws protecting concussed student athletes from returning to play in the same game, and similar laws are pending in 23 other states, Aubry said.

Revisions to international concussion guidelines are also needed, the panelists argued. The current guidelines were developed in 2008, when the Third International Conference on Concussion in Sport developed the Consensus Statement on Concussion in Sport, which lays out evidence-based guidelines for physicians, trainers and other health care professionals on how to treat concussed patients (http://sportconcussions .com/html/Zurich\%20Statement.pdf). An update is expected to be released after a conference to be held in Zurich, Switzerland in November 2012. Jordan Fallis, Ottawa, Ont.

CMAJ 2011. DOI:10.1503/cmaj.109-4080 